\title{
10. SOCIAL CAPITAL
}

\section{Introduction}

The term 'social capital' refers to the institutions, relationships, and norms, that shape social networks, foster trust, and facilitate coordination and cooperation for mutual benefit. ${ }^{1}$ A key concept of social capital is the notion of interlocking networks of relationships between individuals and groups.

Social reciprocity and neighbourhood connection are characterised by a combination of short-term altruism and long-term self interest, where people help each other or act for the benefit of other people at a personal cost with the general expectation that this help will be returned in the future when they might need help themselves. ${ }^{2}$

Trust involves a willingness to take risks in a social context. This willingness is based on a confidence that others will respond as expected and will act in mutually supportive ways, or at least that others will not intend harm. The overall level of trust that people attribute to others has been explored in conjunction with perceptions of safety within the individual's local community.

Individuals acting on their own do not generate social capital; it is generated by people in communities engaging with others through a variety of associations that are voluntary and possibly equitable. Participation in the local community depends on a tendency among people to be social and to form new associations and networks.

The New South Wales Adult Health Survey 2003 included questions on social reciprocity and neighbourhood connection, feelings of trust and safety, and participation in the local community. Respondents were asked the following questions: 'In the past three months, how often have you helped out any local group or organisation such as a school, scouts and brownies, a sporting club, or hospital as a volunteer, or other organisation?', 'In the past six months, how often have you attended a local community event such as a church or school fete, school concert, or a street fair?', 'Are you an active member of a local organisation, church, or club such as a sport or craft or social club?', 'Do you agree or disagree with the statement, "I feel safe walking down my street after dark"?', 'Do you agree or disagree with the statement, "Most people can be trusted"?', 'Do you agree or disagree with the statement, "My area has a reputation for being a safe place"?', 'If you were caring for a child and needed to go out for a while, and could not take the child with you, would you ask someone in your neighbourhood for help?', 'How often have you visited someone in your neighbourhood in the past week?', 'When you go shopping in your local area how often are you likely to run into friends and acquaintances?', 'Would you be sad if you had to leave this neighbourhood?'.

\section{Results}

Social reciprocity and neighbourhood connection

Responses to the questions on social reciprocity and neighbourhood connection were grouped into positive and negative responses. Responses of 'yes' to the questions 'If you were caring for a child and needed to go out for a while, and could not take the child with you, would you ask someone in your neighbourhood for help?' and 'Would you be sad if you had to leave this neighbourhood', as well as responses of at least 'once' to the question 'How often have you visited someone in your neighbourhood in the last week', and responses of at least 'some of the time' to the question 'When you go shopping in your local area, how often are you likely to run into friends and acquaintances?' were combined into positive responses. The question 'How often have you visited someone in your neighbourhood in the past week?' has been used as an example of social reciprocity and neighbourhood connection and analysed further.

Overall, in 2003, 73.0 per cent of the population said they would ask someone in their neighbourhood for help with caring for a child if they needed to go out for a while. There was no significant difference between the proportion of males (74.2 per cent) and females (71.9 per cent) who would ask someone in their neighbourhood for help with a child.

Nearly three-quarters (73.1 per cent) of the population stated they would be sad if they had to leave their neighbourhood. A significantly greater proportion of females (76.8 per cent) than males (69.4 per cent) said they would be sad to leave their neighbourhood.

A total of 81.6 per cent of the population stated that they run into friends and acquaintances in their local area at least 'sometimes'. There was no significant difference between the proportion of females ( 82.8 per cent) and males ( 80.3 per cent) who said they ran into friends and acquaintances in their local area.

Almost two-thirds (65.4 per cent) of the population reported that they had visited someone in their neighbourhood in the past week. There was no significant difference between the proportion of males (67 per cent) and females (63.8 per cent) who had visited someone in their neighbourhood. The proportion of people who visited a neighbour did not vary significantly by age.

There was significant geographic variation in the proportion of residents who had visited someone in their neighbourhood in the past week, with a significantly greater proportion of rural residents $(72.3$ per cent $)$ than urban residents (63.5 per cent) having visited someone in their neighbourhood. 
A significantly greater proportion of people in the second most disadvantaged quintile (68.8 per cent) were likely to have visited their neighbours in the last week.

There was no significant change in the proportion of people visiting neighbours between 2002 (65.9 per cent) and 2003 (65.4 per cent).

\section{Trust and safety}

In analysing the trust and safety questions, responses of 'strongly agree' and 'agree' to the questions 'I feel safe walking down my street after dark', 'Most people can be trusted', and 'My area has a reputation for being a safe place', were combined into 'positive' responses. The question 'Most people can be trusted' has been used as an example of trust and safety and analysed further.

Overall, in 2003, 68.3 per cent of the population strongly agreed or agreed with the statement that 'I feel safe walking down my street after dark'. There was a significantly greater proportion of males (80.2 per cent) than females (56.6 per cent) who felt safe walking down their street after dark.

Nearly three-quarters ( 74.8 per cent) of the population strongly agreed or agreed with the statement 'My area has a reputation for being a safe place'. A significantly greater proportion of males (76.5 per cent) than females (73.1 per cent) agreed that their area was safe.

A total of 69.6 per cent of the population strongly agreed or agreed with the statement 'Most people can be trusted'. A significantly greater proportion of males (71.5 per cent) than females (67.9 per cent) agreed that most people could be trusted. Among females, a significantly lower proportion aged 16-24 years (59.9 per cent) and a significantly greater proportion aged 75 years and over (76.6 per cent) agreed that most people can be trusted, compared to the overall female population. Among males, a significantly greater proportion aged 75 years and over (78.3 per cent) agreed that most people can be trusted, compared to the overall male population.

There was no significant variation in the proportion of residents in rural areas (71.7 per cent) and urban areas (69.1 per cent) who strongly agreed or agreed with the statement 'Most people can be trusted'.

There was significant variation based on socioeconomic disadvantage. The proportion of people who agreed that 'Most people can be trusted' decreased as socioeconomic disadvantage increased. A significantly greater proportion of people in the least (79.2 per cent) and second least disadvantaged quintiles (73.8 per cent), and a significantly lower proportion of people in the most disadvantaged quintile (57.4 per cent) agreed that most people can be trusted, compared to the overall population.

The proportion of people who felt most people can be trusted increased significantly between 2002 (65.9 per cent) and 2003 (69.6 per cent).

\section{Participation in the local community}

Responses to the questions on participation in the local community were grouped into positive or negative responses. Responses of 'at least once' to the questions 'In the past three months, how often have you helped out any local group or organisation such as a school, scouts and brownies, a sporting club or a hospital as a volunteer, or other organisation?', and 'In the past three months, how often have you attended a local community event such as a church fete, school fete, school concert, or street fair?', and of 'yes' to the question 'Are you an active member of a local organisation, church or club such as a sport, craft, or social club?', were combined into 'positive' responses. The question 'In the past six months, how often have you attended a local community event such as a church or school fete, school concert, or a street fair?' has been used as an example of participation in the local community and analysed further.

Overall, in 2003, almost one-third (32.1 per cent) of the population reported that they had helped out a local group or organisation in the past three months. There was no significant difference in the proportion of males (31.2 per cent) and females (32.9 per cent) who had helped out any local group or organisation in the past three months. Nearly half (43.5 per cent) of the population said they were active members of a local organisation. A significantly greater proportion of males (45.4 per cent) reported that they were active members of a local organisation than females (41.7 per cent).

More than half (58.1 per cent) of the population reported that they had attended a local community event in the past six months. A significantly greater proportion of females (62.0 per cent) than males (54.1 per cent) had attended a local community event in the last six months. Among females, a significantly lower proportion aged 65 years and over ( 46.2 per cent to 52.4 per cent), and a significantly greater proportion aged $35-44$ years (74.6 per cent), had attended a local community event in the last six months, compared to the overall female population. A significantly lower proportion of males aged 65 years and over ( 44.3 per cent to 44.6 per cent) and a significantly greater proportion of males aged $35-44$ years (65.9 per cent) had attended a local community event, compared to the overall male population.

A significantly greater proportion of rural residents (63.7 per cent) than urban residents (56.5 per cent) had attended a local community event in the last six months.

There was significant variation in the proportion of people participating in local community events based on level of socioeconomic disadvantage. A significantly greater proportion of people in the quintile of least socioeconomic disadvantage (62.8 per cent) and a significantly lower proportion of people in the quintile of most socioeconomic disadvantage (51.6 per cent) were likely to have participated in a local community event. 
The proportion of people attending a local community event did not change significantly between 2002 (56.8 per cent) and 2003 (58.1 per cent).

Figure 92 shows participation in the local community and Figures 93-94 show attendance at a community event at least once in the last six months by age and socioeconomic disadvantage score. Figure 95 shows trust and safety in the local area and Figures 96-97 show the proportion of people who say most people can be trusted, by age and socioeconomic disadvantage score. Figure 98 shows reciprocity-social engagement and Figures 99-100 show the proportion of people who visit neighbours, by age and socioeconomic disadvantage score.

\section{References}

1. World Bank. What is Social Capital? Available online at www.worldbank.org/poverty/scapital/whatsc.htm. Accessed 1 July 2003.

2. Onyx J, Bullen P. Measuring Social Capital in Five Communities in NSW: An analysis. Sydney: Centre for Australasian Community Organisations and Management, 1997.

\section{FIGURE 92}

\section{PARTICIPATE IN THE LOCAL COMMUNITY, PERSONS AGED 16 YEARS AND OVER, NSW, 2003}
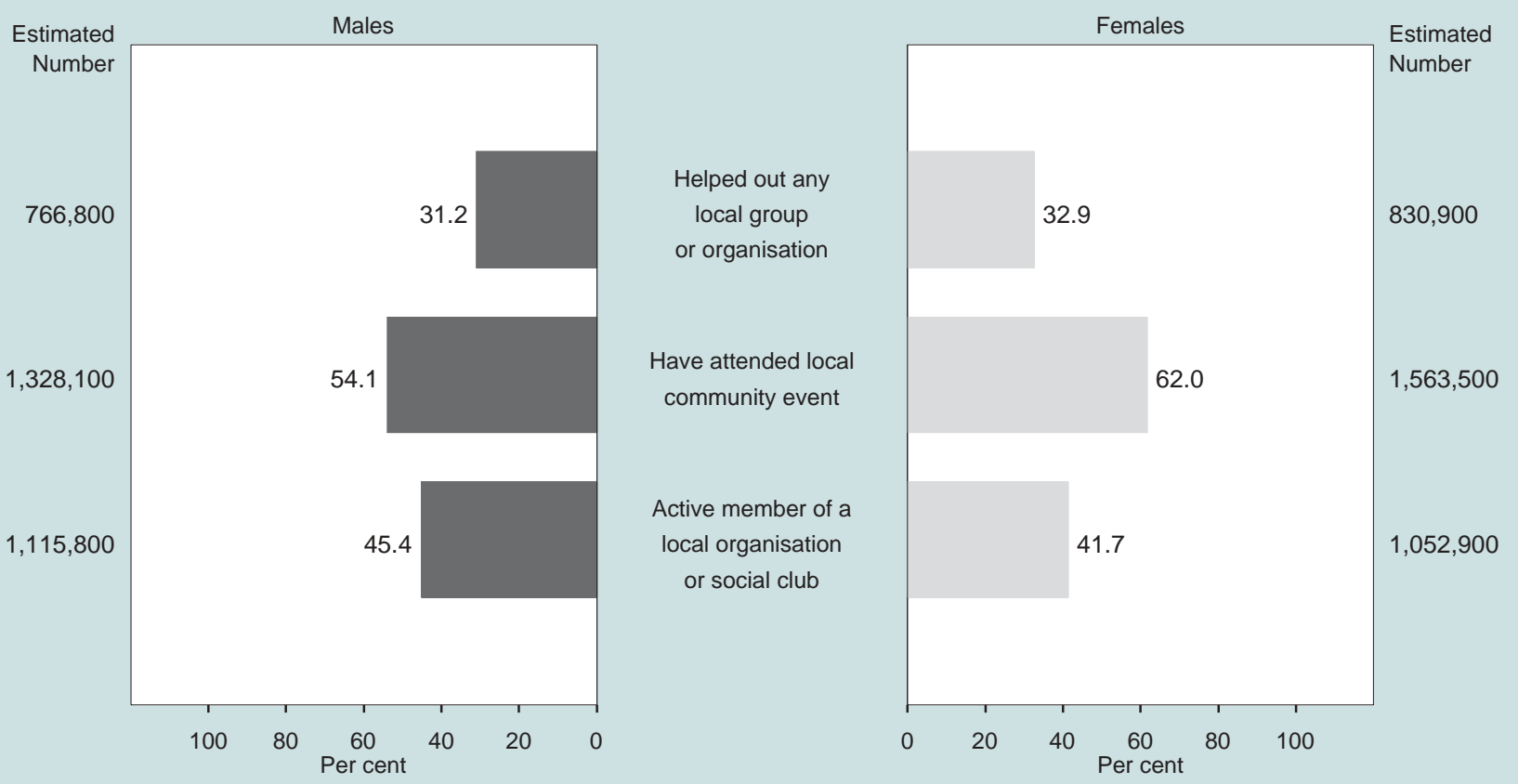

Source: NSW Adult Health Survey 2003 (HOIST), Centre for Epidemiology and Research, NSW Department of Health. 


\section{FIGURE 93}

ATTENDED A COMMUNITY EVENT AT LEAST ONCE INTHE LAST SIX MONTHS BY AGE, PERSONS AGED 16 YEARS AND OVER, NSW, 2003

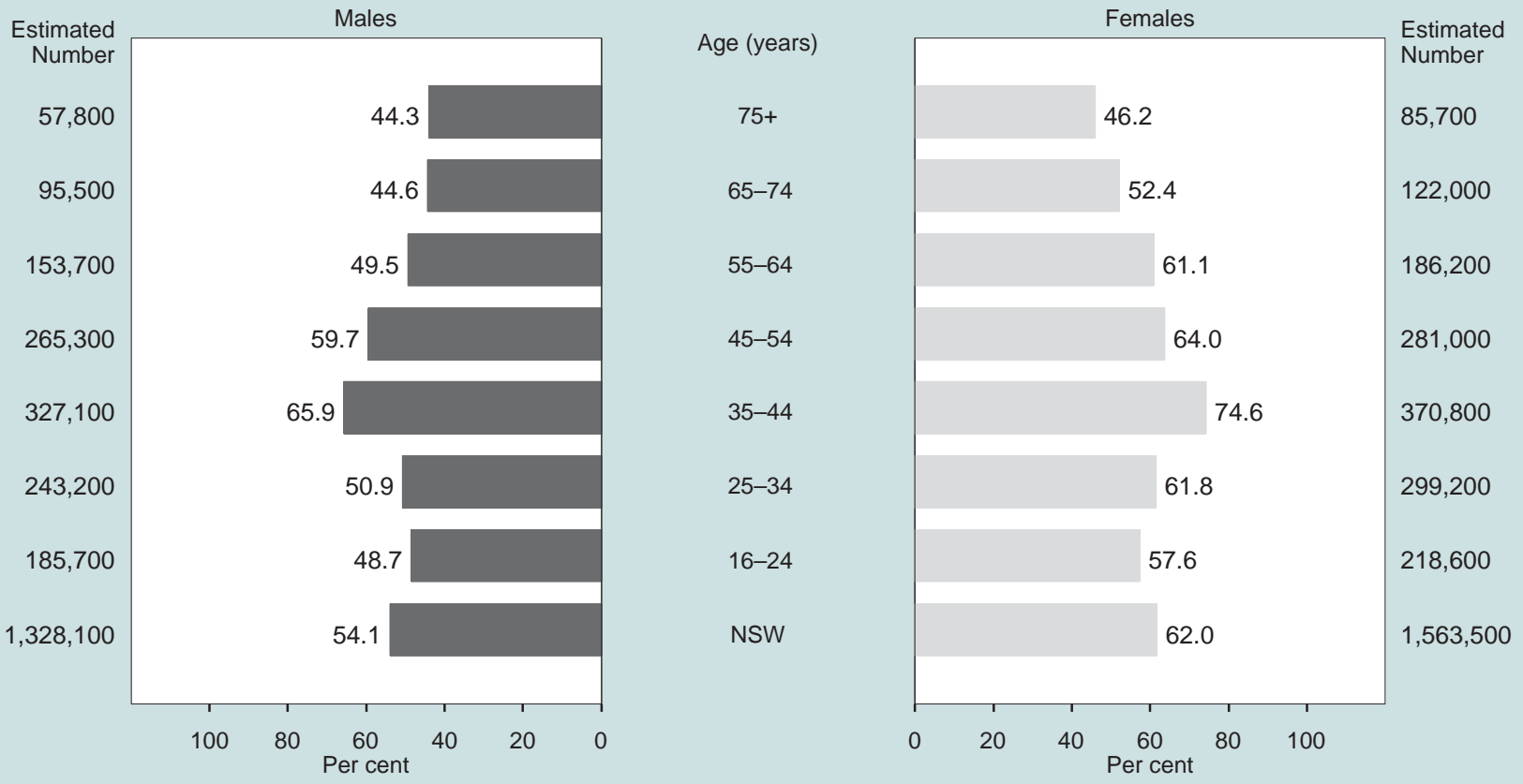

Source: NSW Adult Health Survey 2003 (HOIST), Centre for Epidemiology and Research, NSW Department of Health.

\section{FIGURE 94}

ATTENDED A COMMUNITY EVENT AT LEAST ONCE INTHE LAST SIX MONTHS BY SOCIOECONOMIC DISADVANTAGE SCORE, PERSONS AGED 16 YEARS AND OVER, NSW, 2003
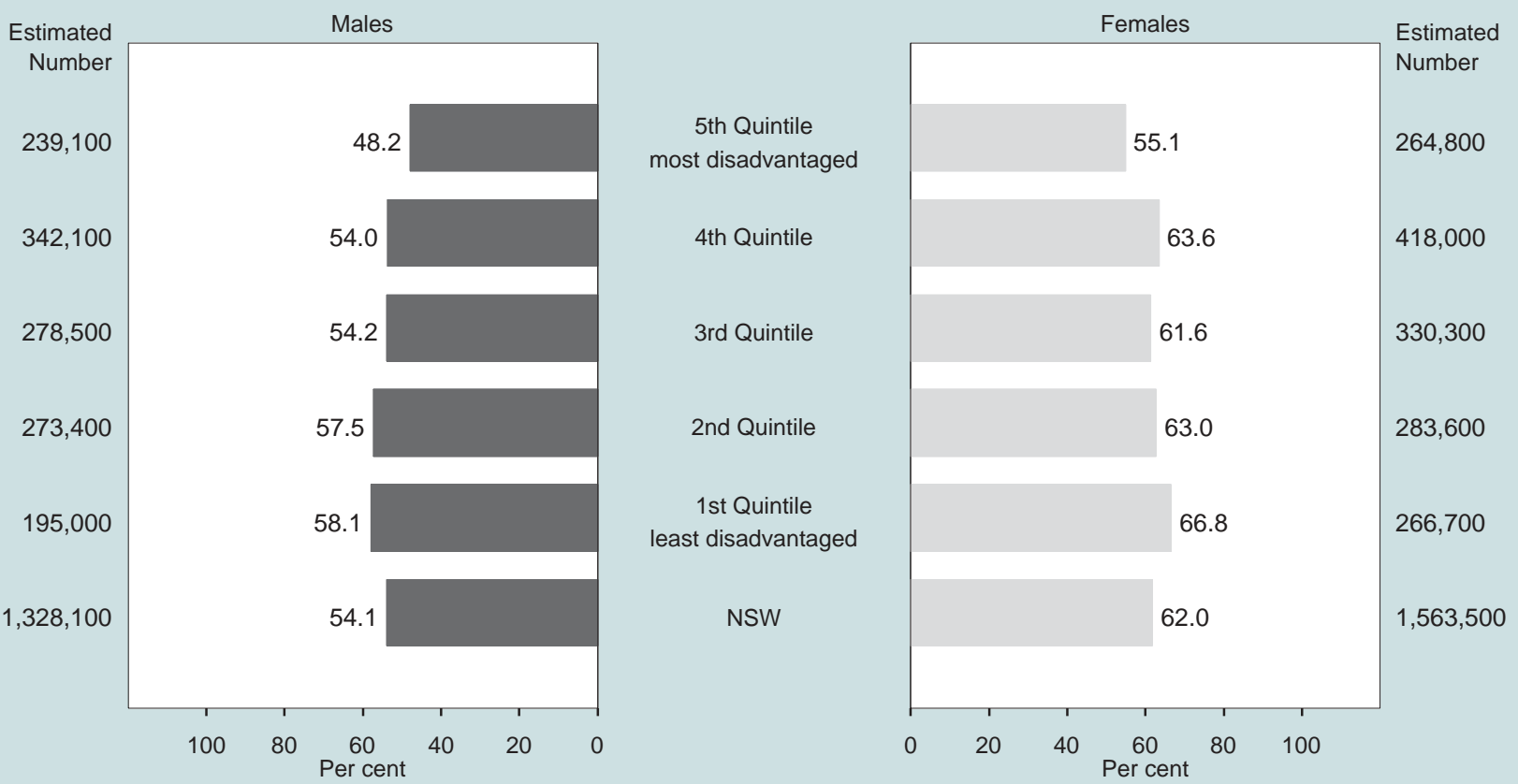

Source: NSW Adult Health Survey 2003 (HOIST), Centre for Epidemiology and Research, NSW Department of Health. 


\section{FIGURE 95}

TRUST AND SAFETY IN LOCAL AREA, PERSONS AGED 16 YEARS AND OVER, NSW, 2003
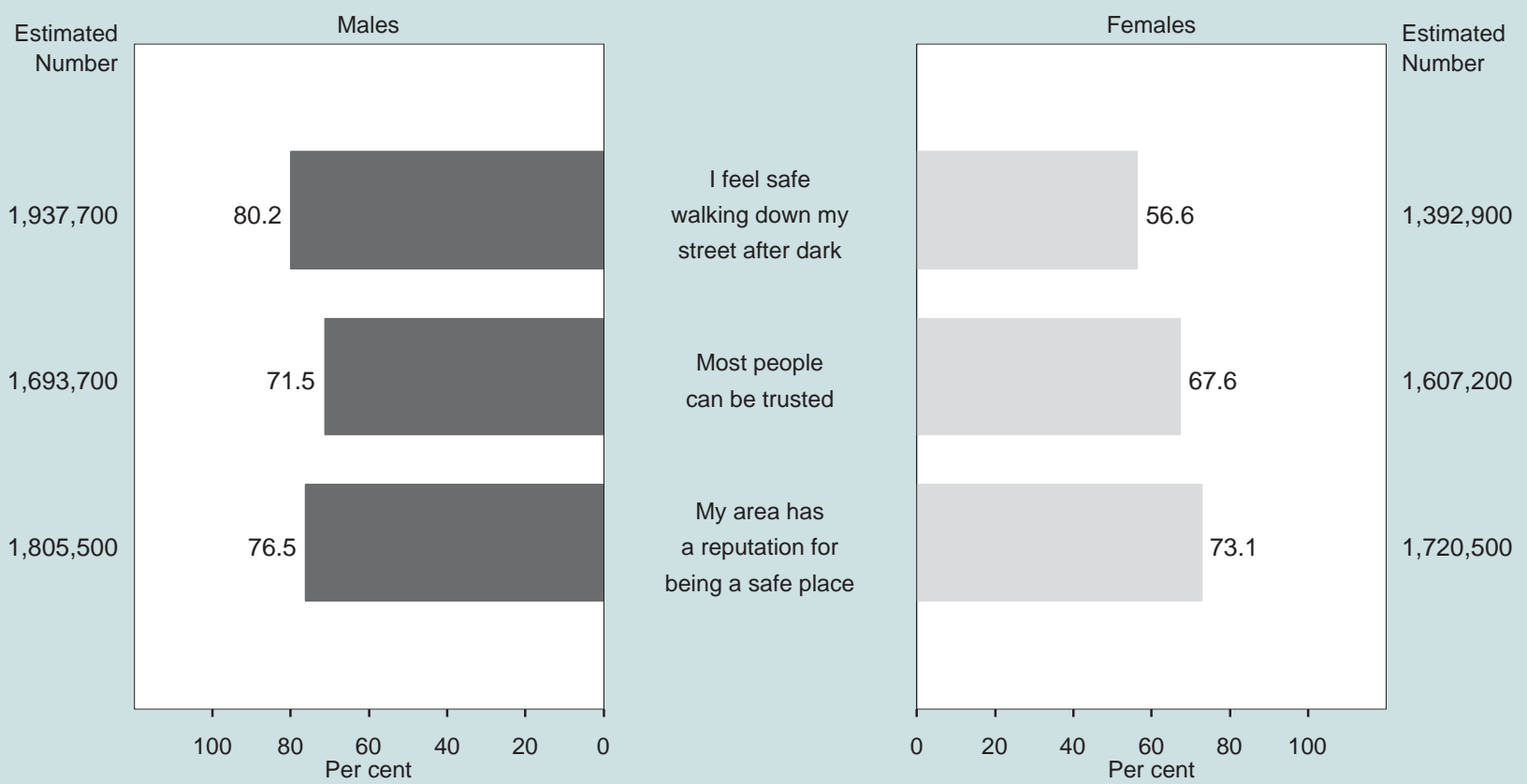

Source: NSW Adult Health Survey 2003 (HOIST), Centre for Epidemiology and Research, NSW Department of Health.

\section{FIGURE 96}

MOST PEOPLE CAN BE TRUSTED, BY AGE, PERSONS AGED 16 YEARS AND OVER, NSW, 2003

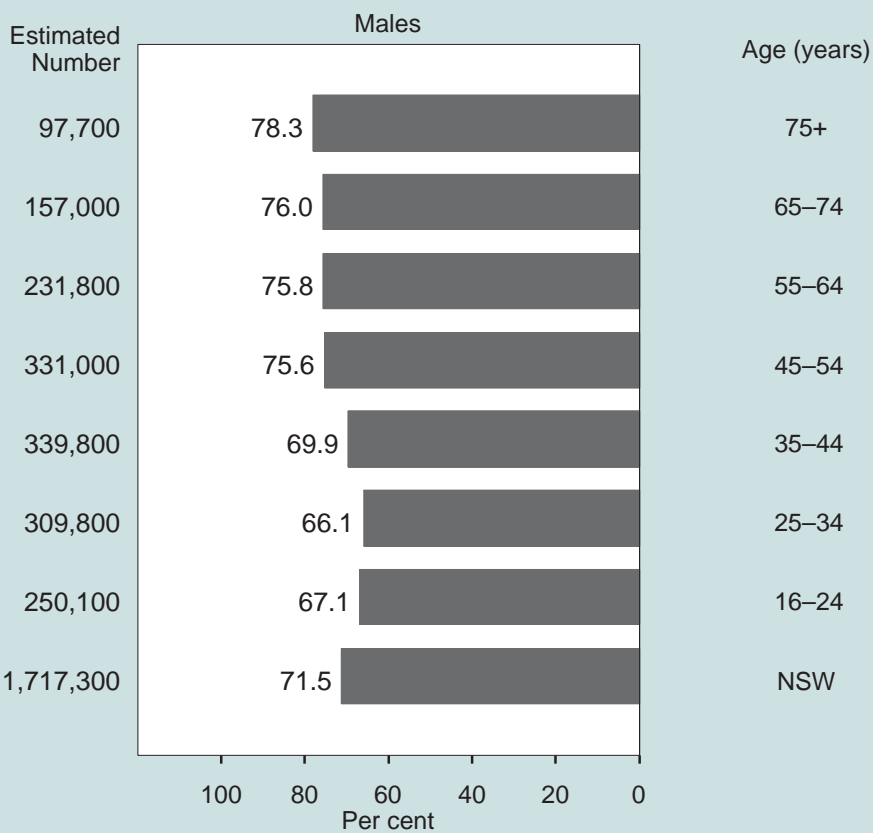

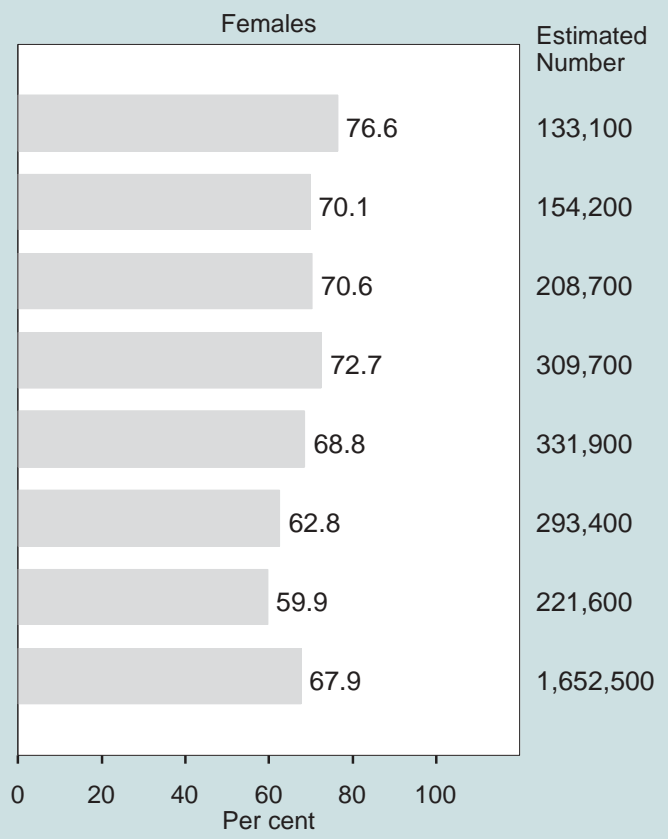

Source: NSW Adult Health Survey 2003 (HOIST), Centre for Epidemiology and Research, NSW Department of Health. 


\section{FIGURE 97}

MOST PEOPLE CAN BE TRUSTED, BY SOCIOECONOMIC DISADVANTAGE SCORE, PERSONS AGED 16 YEARS AND OVER, NSW, 2003

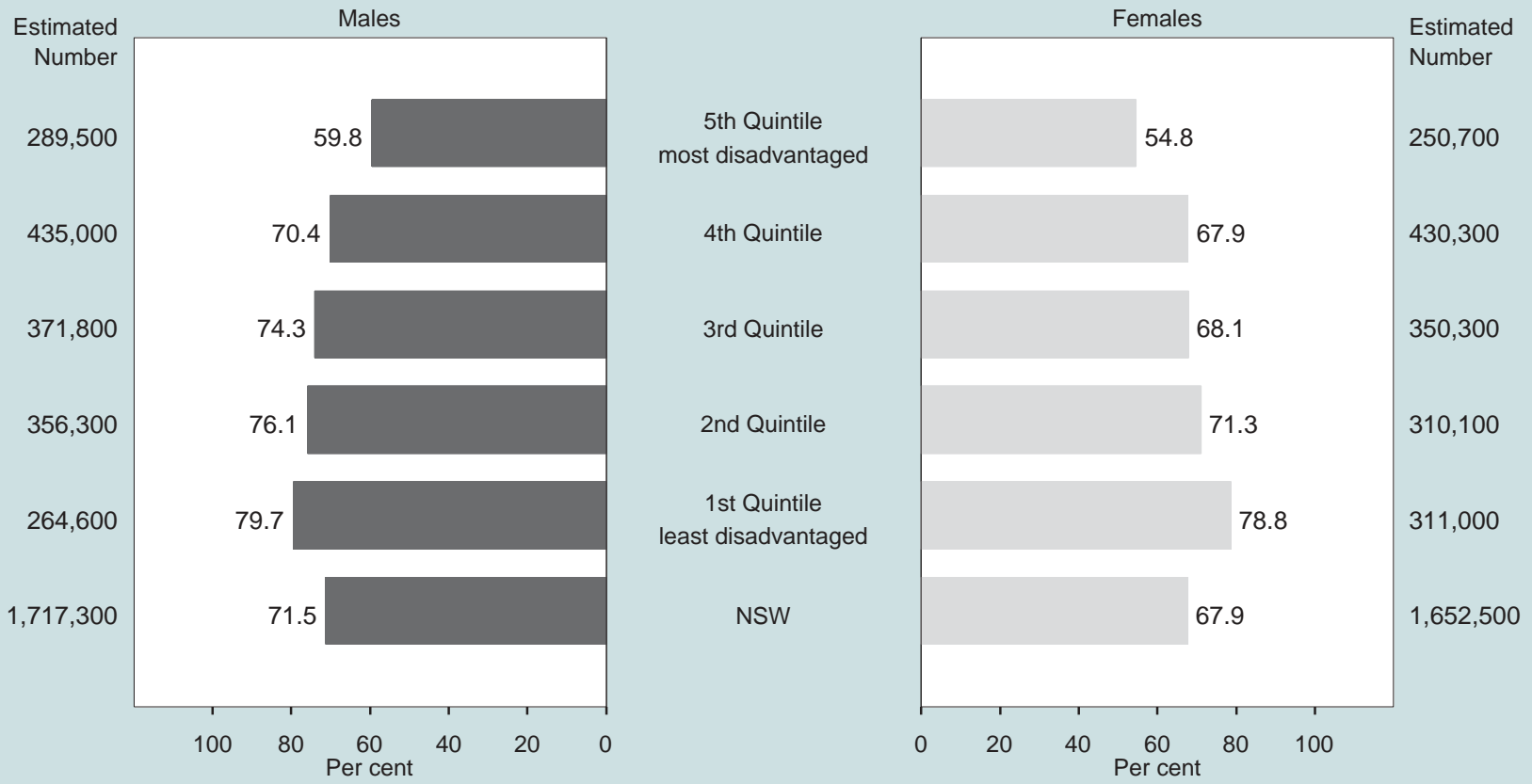

Source: NSW Adult Health Survey 2003 (HOIST), Centre for Epidemiology and Research, NSW Department of Health.

\section{FIGURE 98}

RECIPROCITY-SOCIAL ENGAGEMENT, PERSONS AGED 16 YEARS AND OVER, NSW, 2003
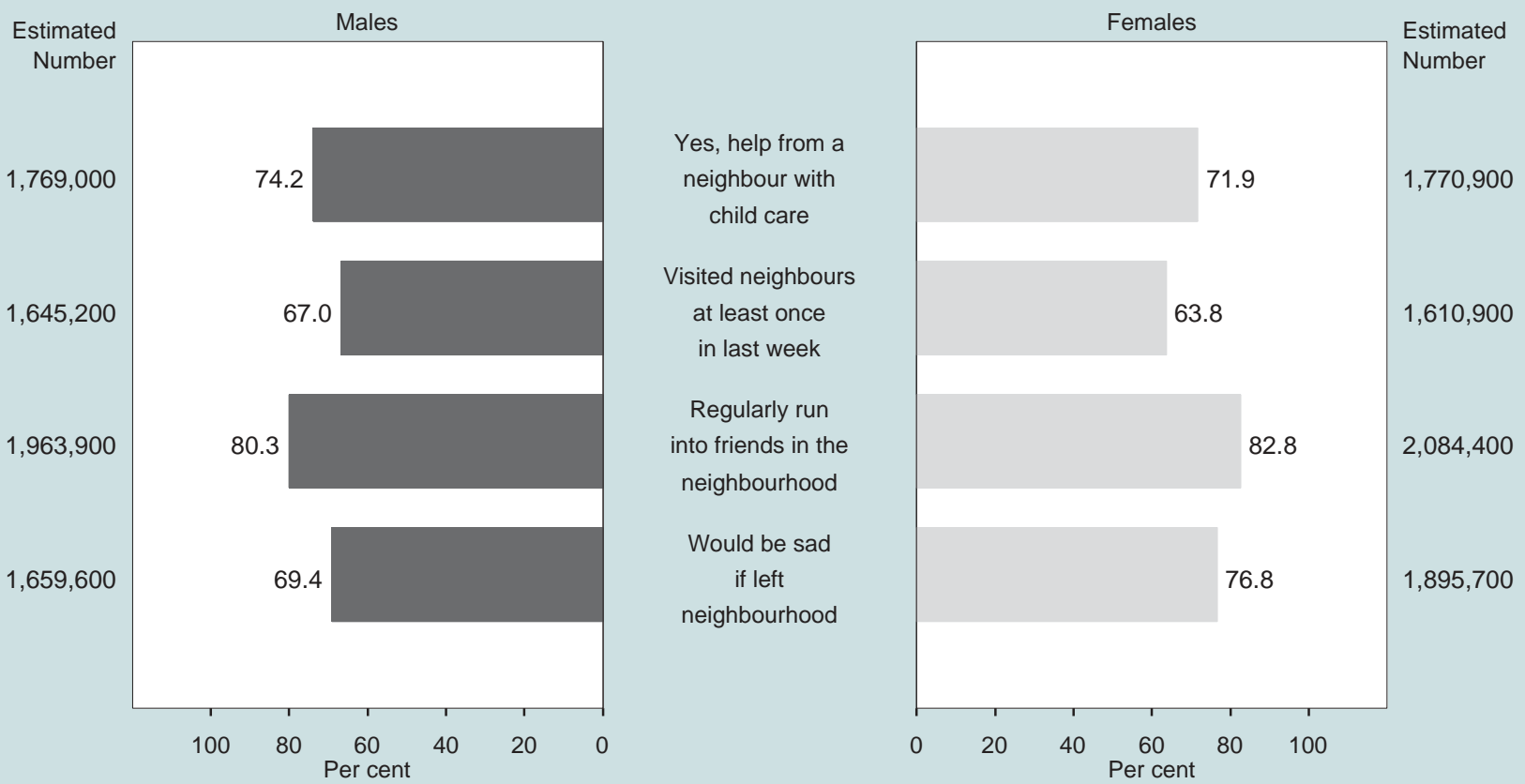

Source: NSW Adult Health Survey 2003 (HOIST), Centre for Epidemiology and Research, NSW Department of Health. 


\section{FIGURE 99}

\section{VISIT NEIGHBOURS, BY AGE, PERSONS AGED 16 YEARS AND OVER, NSW, 2003}

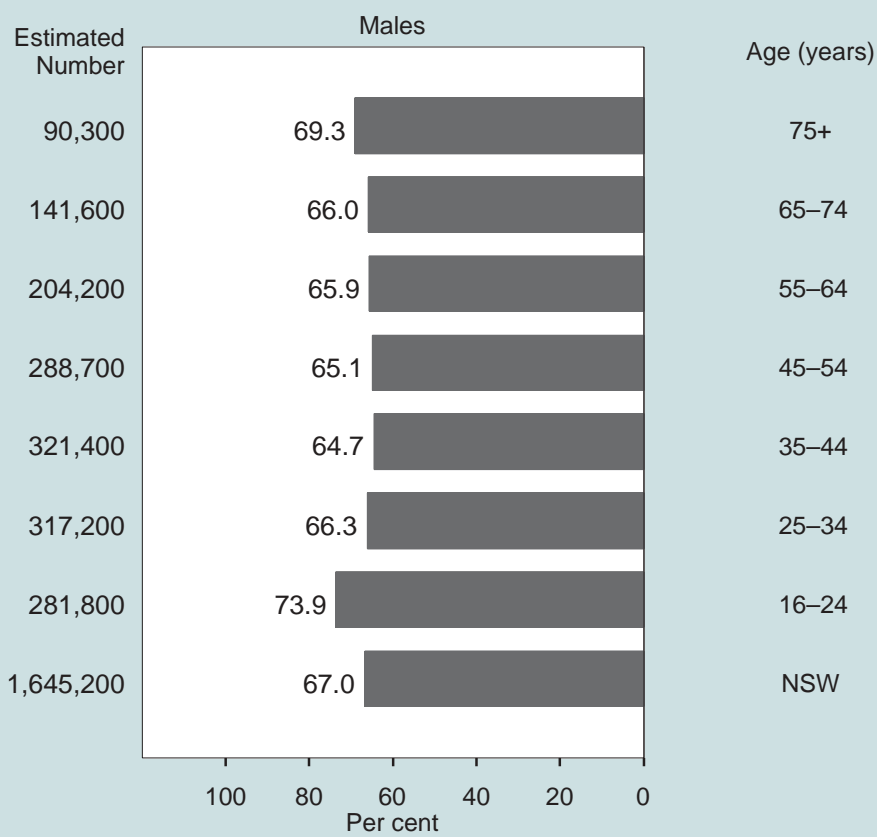

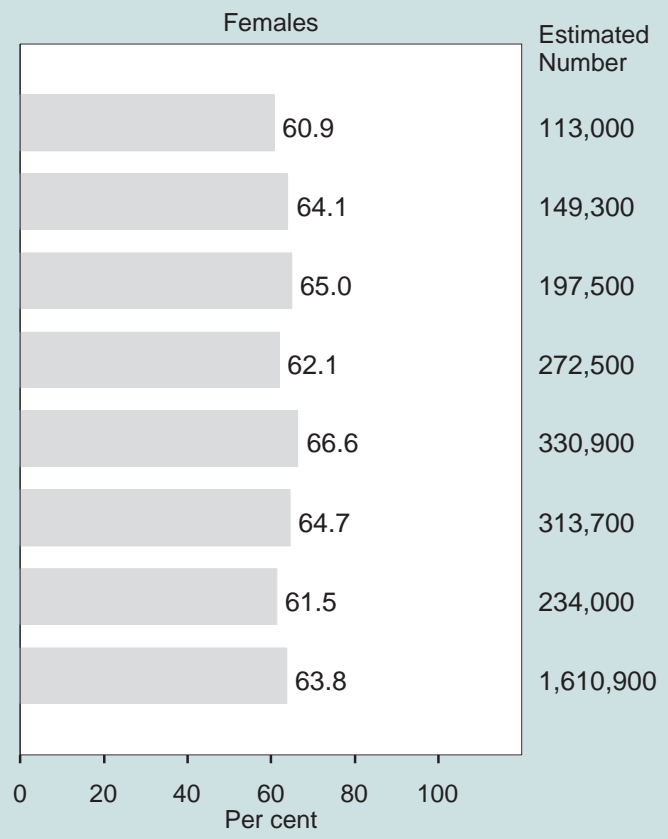

Source: NSW Adult Health Survey 2003 (HOIST), Centre for Epidemiology and Research, NSW Department of Health.

\section{FIGURE 100}

VISIT NEIGHBOURS, BY SOCIOECONOMIC DISADVANTAGE SCORE, PERSONS AGED 16 YEARS AND OVER, NSW, 2003

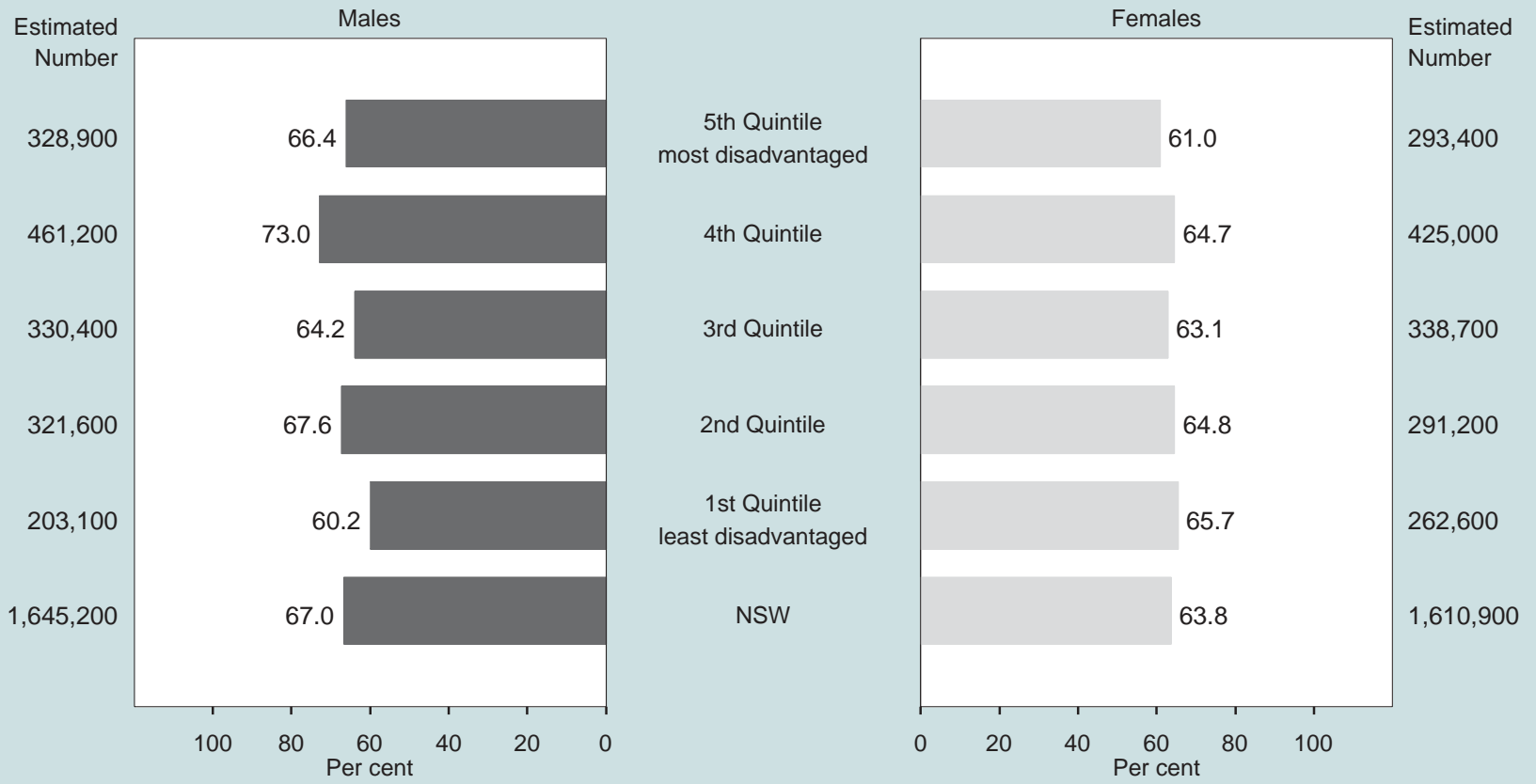

Source: NSW Adult Health Survey 2003 (HOIST), Centre for Epidemiology and Research, NSW Department of Health. 